DOI: $10.1515 / \mathrm{amm}-2016-0081$

J. GONDRO*,\#, K. BŁOCH*, P. BRĄGIEL**, M. NABIAŁEK*, M. SZOTA***

\title{
CURIE TEMPERATURE AND MICROSTRUCTURAL CHANGES DUE TO THE HEATING TREATMENT OF MAGNETIC AMORPHOUS MATERIALS
}

\begin{abstract}
Three distinct alloys: $\mathrm{Fe}_{86} \mathrm{Zr}_{7} \mathrm{Nb}_{1} \mathrm{Cu}_{1} \mathrm{~B}_{5}, \mathrm{Fe}_{82} \mathrm{Zr}_{7} \mathrm{Nb}_{2} \mathrm{Cu}_{1} \mathrm{~B}_{8}$, and $\mathrm{Fe}_{81} \mathrm{Pt}_{5} \mathrm{Zr}_{7} \mathrm{Nb}_{1} \mathrm{Cu}_{1} \mathrm{~B}_{5}$ were characterized both magnetically and structurally. The samples, obtained with spinning roller method as a ribbons $3 \mathrm{~mm}$ in width and $20 \mu \mathrm{m}$ thick, were investigated as-quenched and after each step of a multi steps heating treatment procedure. Each sample was annealed at four steps, fifteen minutes at every temperature, starting from $573 \mathrm{~K}+600 \mathrm{~K}$ up to $+700 \mathrm{~K}$ depending on type of alloy. Mössbauer spectroscopy data and transmission electron microscope (HREM) pictures confirmed that the as-quenched samples are fully amorphous. This is not changed after the first stages of treatment heating leads to a reduction of free volumes. The heating treatment has a great influence on the magnetic susceptibilities. The treatment up to $600 \mathrm{~K}$ improves soft magnetic properties: an $\chi$ increase was observed, from about 400 to almost 1000 for the samples of alloys without Pt, and from about 200 to 450 at maximum, for the $\mathrm{Fe}_{81} \mathrm{Pt}_{5} \mathrm{Zr}_{7} \mathrm{Nb}_{1} \mathrm{Cu}_{1} \mathrm{~B}_{5}$. Further heating, at more elevated temperatures, leads to magnetic hardening of the samples. Curie temperatures, established from the location of Hopkinson's maxima on the $\chi(\mathrm{T})$ curve are in very good agreement with those obtained from the data of specific magnetization, $\sigma(\mathrm{T})$, measured in a field of $0.75 \mathrm{~T}$. As a critical parameter $\beta$ was chosen to be equal 0.36 for these calculations, it confirmed that the alloys may be considered as ferromagnetic of Heisenberg type. Heating treatment resulted in decreasing of TC. These changes are within a range of several K.

Keywords: amorphous alloys, magnetic properties, magnetic susceptibility, Mössbauer spectroscopy, Curie temperature
\end{abstract}

\section{Introduction}

The amorphous alloys, due to lack of a long range order, are materials with a complex magnetic structure [1-3]. Alloys magnetic structure and magnetic properties are strongly influenced by a chemical composition and thermal treatment conditions [4-7]. As the magnetic alloys usually consist not only transition metals atoms but also other atoms with different atomic radii, heating treatment, even at a temperature slightly higher than the ambient temperature [8-10].

The iron-based soft magnetic materials make up an interesting group, for scientific and industrial applications. An especially interesting of this group of materials which feature Curie temperatures that are close to room temperature. These materials could be used in production of magnetic fridges. Also, use of appropriate heat treatment, nanocrystalline alloys can be obtained, with of nanometric grains of the $\alpha$-Fe phase and amorphous matrix [11]. The nanocrystalline materials have good magnetic properties and they are widely used include electronics and electrical engineering.

In this paper, investigations are presented into the: microstructure, magnetic ordering, thermal stability and magnetocaloric effect occurring in samples of amorphous multicomponent: $\mathrm{Fe}_{86} \mathrm{Zr}_{7} \mathrm{Nb}_{1} \mathrm{Cu}_{1} \mathrm{~B}_{5}, \mathrm{Fe}_{82} \mathrm{Zr}_{7} \mathrm{Nb}_{2} \mathrm{Cu}_{1} \mathrm{~B}_{8}$, and
$\mathrm{Fe}_{81} \mathrm{Pt}_{5} \mathrm{Zr}_{7} \mathrm{Nb}_{1} \mathrm{Cu}_{1} \mathrm{~B}_{5}$ alloys in the as-quenched state and after a multilevel thermal annealing process.

\section{Experimental procedure}

The alloys were prepared from stoichiometric quantities of the analytically pure components, arc melted in argon protected atmosphere. The ribbons, $3 \mathrm{~mm}$ in width and about $20 \mu \mathrm{m}$ thick, were obtained from this melt by rapid quenching on a single $\mathrm{Cu}$ spinning roller. This was also done in argon atmosphere. Samples were investigated both as they were obtained and after every step of a multistep heating treatment. To avoid an influence of the possible inhomogeneities, all the measurements, for a one type of the alloy, were conducted on the same sample, changed only in a next step of the heating treatment. Each step had been fifteen minutes long, in a evacuated quartz ampoule, which was opened only after cooling to the room temperature. The heating treatment for investigated alloys was performed in temperature range from $573 \mathrm{~K}$ to $700 \mathrm{~K}$, in four steps.

Samples were investigated to elucidate their microstructure and magnetic properties. For structural properties room temperature Mössbauer spectra were recorded - Polon spectrometer with $50 \mathrm{mCi}{ }^{57} \mathrm{Co}(\mathrm{Rh})$ source [12],

* CZESTOCHOWA UNIVERSITY OF TECHNOLOGY, INSTITUTE OF PHYSICS, FACULTY OF PRODUCTION ENGINEERING AND MATERIALS TECHNOLOGY, 19 ARMII KRAJOWEJ AV., 42-200 CZESTOCHOWA, POLAND

** JAN DLUGOSZ UNIVERSITY OF CZESTOCHOWA, FACULTY OF MATHEMATICS AND NATURAL SCIENCES, INSTITUTE OF PHYSICS, 15 ARMII KRAJOWEJ AV., 42-200 CZĘSTOCHOWA, POLAND

*** CZESTOCHOWA UNIVERSITY OF TECHNOLOGY, INSTITUTE OF MATERIALS ENGINEERING, FACULTY OF PRODUCTION ENGINEERING AND MATERIALS TECHNOLOGY, 19 ARMII KRAJOWEJ AV., 42-200 CZĘSTOCHOWA, POLAND

\# Corresponding author: 23kasia1@wp.pl 
and transmission electron microscope (HREM) pictures were analyzed -obtained on JEM 3010. Magnetic properties measurements included: low field magnetic susceptibility measurements $(\chi)$ in $0.26 \mathrm{~A} / \mathrm{m}, 2 \mathrm{kHz}$ magnetic field, during 2 seconds from the sample demagnetization.-the transformer method was used; force magnetometer, for fields up to $0.75 \mathrm{~T}$, in temperature range from $223 \mathrm{~K}$ to $373 \mathrm{~K}$ and from $298 \mathrm{~K}$ to $408 \mathrm{~K}$ for alloys without $\mathrm{Pt}$ and with $\mathrm{Pt}$ respectively was the tool for recording $\sigma\left(\mu_{0} H\right)$ curves. Differential Scanning Calorimetry (DSC) [13] measurements were done with Netzsch STA 409C instrument, for the heating rate $10 \mathrm{~K}$ per minute, in argon atmosphere.

\section{Results and discussion}

The Mössbauer spectra for the considered alloys [14] are presented in fig. 1, 2, 3 .

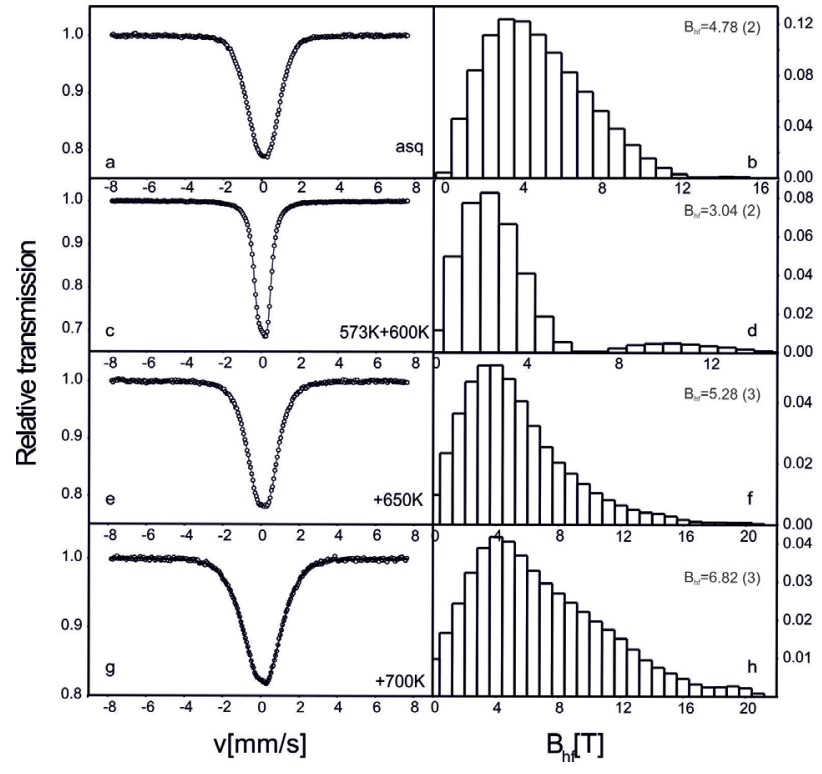

Fig. 1. Mössbauer spectra (a, c, e, g) and corresponding hyperfine field induction distributions ( $b, \mathrm{~d}, \mathrm{f}, \mathrm{h}$ ) for $\mathrm{Fe}_{86} \mathrm{Zr}_{7} \mathrm{Nb}_{1} \mathrm{Cu}_{1} \mathrm{~B}_{5}$ alloy

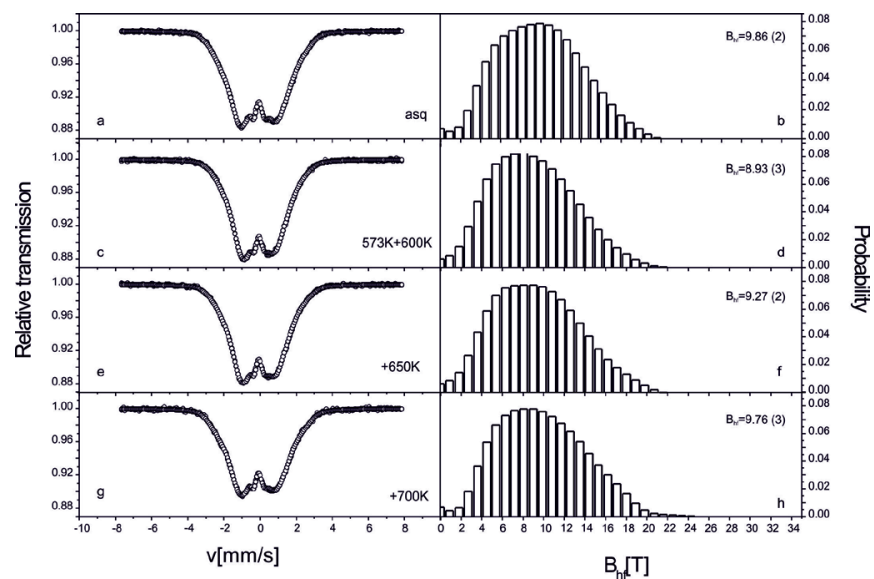

Fig. 2. Mössbauer spectra (a, c, e, g) and corresponding hyperfine field induction distributions (b, d, f, h) for $\mathrm{Fe}_{82} \mathrm{Zr}_{7} \mathrm{Nb}_{2} \mathrm{Cu}_{1} \mathrm{~B}_{8}$ alloy

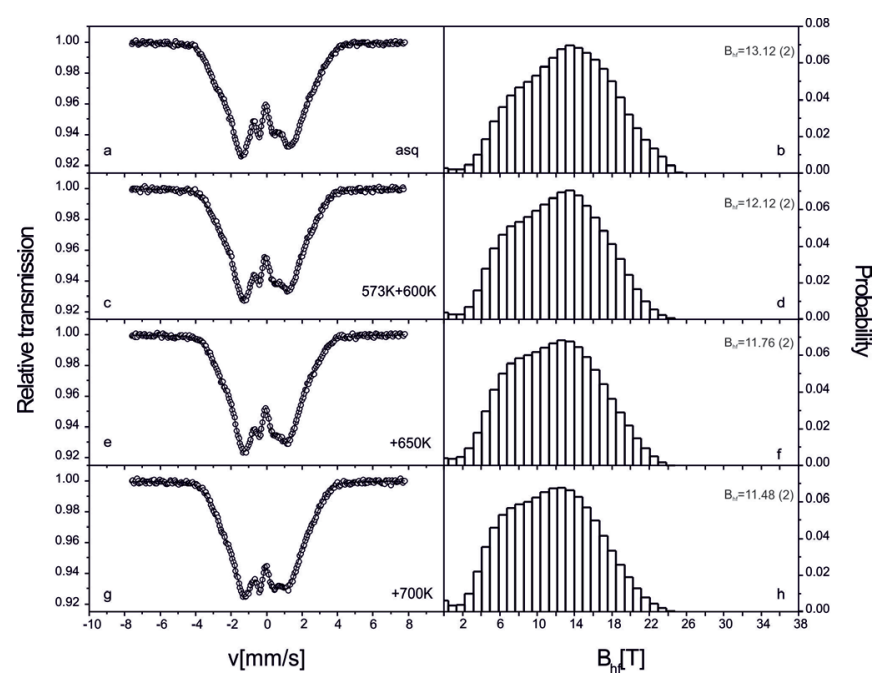

Fig. 3. Mössbauer spectra (a, c, e, g) and corresponding hyperfine field induction distributions ( $\mathrm{b}, \mathrm{d}, \mathrm{f}, \mathrm{h}$ ) for $\mathrm{Fe}_{81} \mathrm{Pt}_{5} \mathrm{Zr}_{7} \mathrm{Nb}_{1} \mathrm{Cu}_{1} \mathrm{~B}_{5}$ alloy

Spectrum for the as quenched $\mathrm{Fe}_{86} \mathrm{Zr}_{7} \mathrm{Nb}_{1} \mathrm{Cu}_{1} \mathrm{~B}_{5}$ alloy is very typical for the amorphous, ferromagnetic, Fe-Zr alloys with a dominant $\mathrm{Fe}$ content $[15,16]$. Heating treatment at $573+600 \mathrm{~K}$ leads to a narrowing of a recorded spectrum. This is accompanied with a increasing of a low field component of a induction of a hyperfine field. Fully amorphous character of the sample, was confirmed by the HREM picture and the electrons diffraction pattern - see figure 4 . The further treatment - heating subsequently at $650 \mathrm{~K}$ and $700 \mathrm{~K}$ gives a broadening of the spectrum and a substantial increase of the high field component of the hyperfine field induction. On the other hand however, data from HREM investigation suggest that samples are still both homogenous and amorphous, see figure 4 .

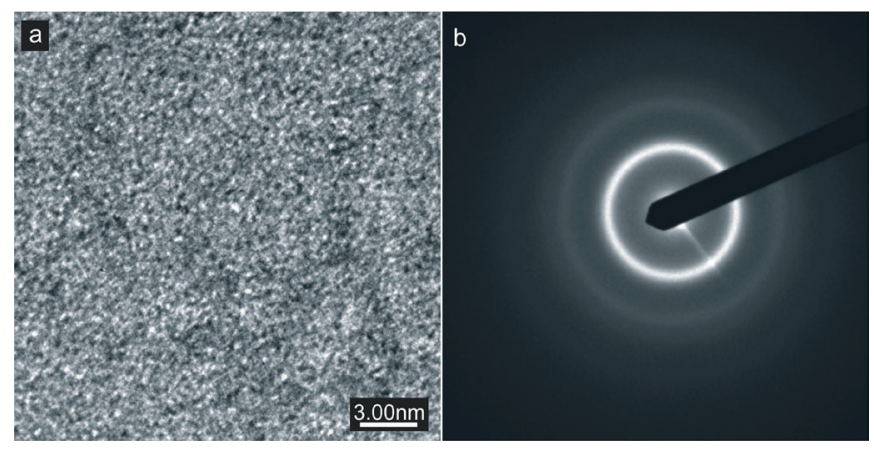

Fig. 4. HREM picture (a) and the electrons diffraction pattern (b) obtained for the as-received $\mathrm{Fe}_{86} \mathrm{Zr}_{7} \mathrm{Nb}_{1} \mathrm{Cu}_{1} \mathrm{~B}_{5}$ alloy

The further treatment - heating subsequently at $650 \mathrm{~K}$ and $700 \mathrm{~K}$ gives a broadening of the spectrum and a substantial increase of the high field component of the hyperfine field induction. On the other hand however, data from HREM investigation suggest that samples are still both homogenous and amorphous, see figure 5.

Such the conclusion found also a support in DSC results: there are any crystallization processes seen up to $750 \mathrm{~K}$, figure 6 .

The primary narrowing of the spectrum may be explained as the result of the free volumes reduction causing a diminishing of the interatomic distances. Why the opposite change in the Mössbauer spectrum is observed after the last two stages of the heating treatment? An explanation may be 
a beginning of a crystal phase nuclei formation process with the grains so fine that they are not recorded by less sensitive measurement techniques. The other possibility is that the samples are staying amorphous but with loss the homogeneity. We may have different types of the local surroundings of the Fe atoms.

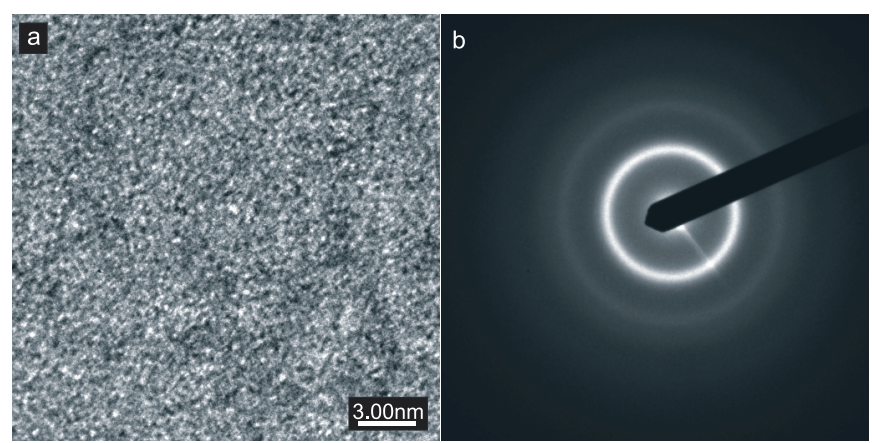

Fig. 5. HREM picture (a) and the electrons diffraction pattern (b) obtained for the $\mathrm{Fe}_{86} \mathrm{Zr}_{7} \mathrm{Nb}_{1} \mathrm{Cu}_{1} \mathrm{~B}_{5}$ alloy after the annealing at $573 \mathrm{~K}+600 \mathrm{~K}+700 \mathrm{~K}$ for $15 \mathrm{~min}$
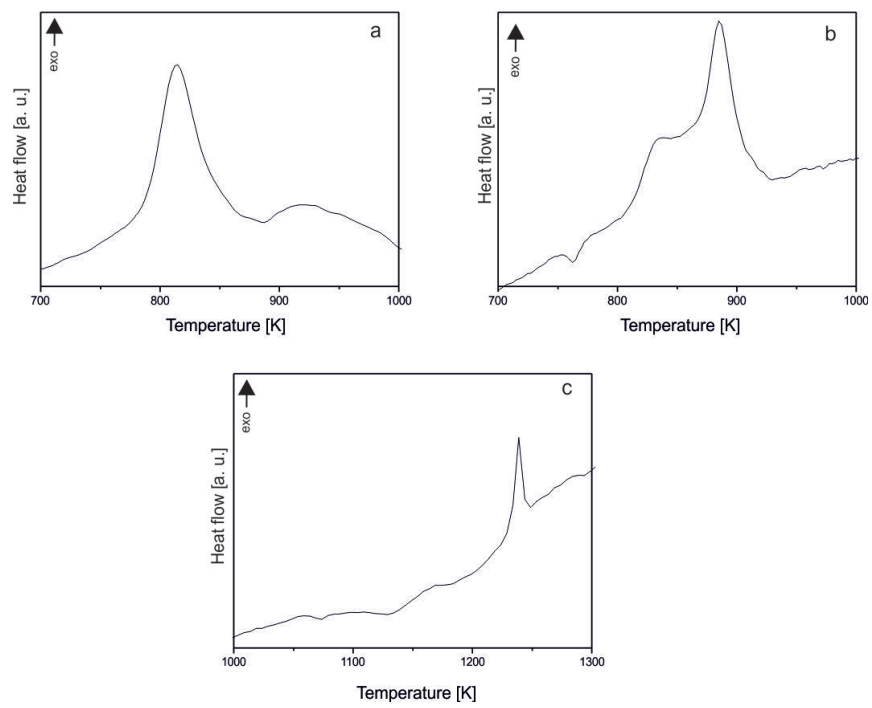

Fig. 6. Isochronal DSC curves recorded at heating rate $10 \mathrm{~K} \mathrm{~min}{ }^{-1}$ for the amorphous alloy: $\mathrm{Fe}_{86} \mathrm{Zr}_{7} \mathrm{Nb}_{1} \mathrm{Cu}_{1} \mathrm{~B}_{5}$ (a), $\mathrm{Fe}_{82} \mathrm{Zr}_{7} \mathrm{Nb}_{2} \mathrm{Cu}_{1} \mathrm{~B}_{8}$ (b), $\mathrm{Fe}_{81} \mathrm{Pt}_{5} \mathrm{Zr}_{7} \mathrm{Nb}_{1} \mathrm{Cu}_{1} \mathrm{~B}_{5}$ (c)

The Mössbauer spectra of the $\mathrm{Fe}_{82} \mathrm{Zr}_{7} \mathrm{Nb}_{2} \mathrm{Cu}_{1} \mathrm{~B}_{8}$ alloys are quite different. They are much more wider, even for the as quenched alloy, then that for the $\mathrm{Fe}_{86} \mathrm{Zr}_{7} \mathrm{Nb}_{1} \mathrm{Cu}_{1} \mathrm{~B}_{5}$ one. An average induction of the hyperfine field is over $100 \%$ greater than in aq $\mathrm{Fe}_{86} \mathrm{Zr}_{7} \mathrm{Nb}_{1} \mathrm{Cu}_{1} \mathrm{~B}_{5}$ case and its' value is only slightly changed after the temperature treatment. The lowest value, obtained for the alloy treated during fifteen minutes at $573 \mathrm{~K}$ and fifteen minutes at $600 \mathrm{~K}$, is only ca. $0.9 \mathrm{~T}$ lower than the appropriate value for the alloy without any treatment. This is over two times less than the value observed for the alloy discussed previously. Despite these differences a shape of the spectrum supports amorphous character of the alloy. When part of the Fe atoms (5\%) had been replaced by platinum atoms a picture of the spectrum was very similar, typical for the amorphous sample with ferromagnetic order but both the spectrum width and the average induction of the hyperfine field were much bigger than in the previous case. Only in the
$\mathrm{Fe}_{81} \mathrm{Pt}_{5} \mathrm{Zr}_{7} \mathrm{Nb}_{1} \mathrm{Cu}_{1} \mathrm{~B}_{5}$ alloy it was observed that the average induction was the biggest for the sample without any heating treatment.

The temperature dependences of the magnetic susceptibility for $\mathrm{Fe}_{86} \mathrm{Zr}_{7} \mathrm{Nb}_{1} \mathrm{Cu}_{1} \mathrm{~B}_{5}, \mathrm{Fe}_{82} \mathrm{Zr}_{7} \mathrm{Nb}_{2} \mathrm{Cu}_{1} \mathrm{~B}_{8}$ and $\mathrm{Fe}_{81} \mathrm{Pt}_{5} \mathrm{Zr}_{7} \mathrm{Nb}_{1} \mathrm{Cu}_{1} \mathrm{~B}_{5}$ are given on figure 7 , figure 8 and figure 9 respectively.

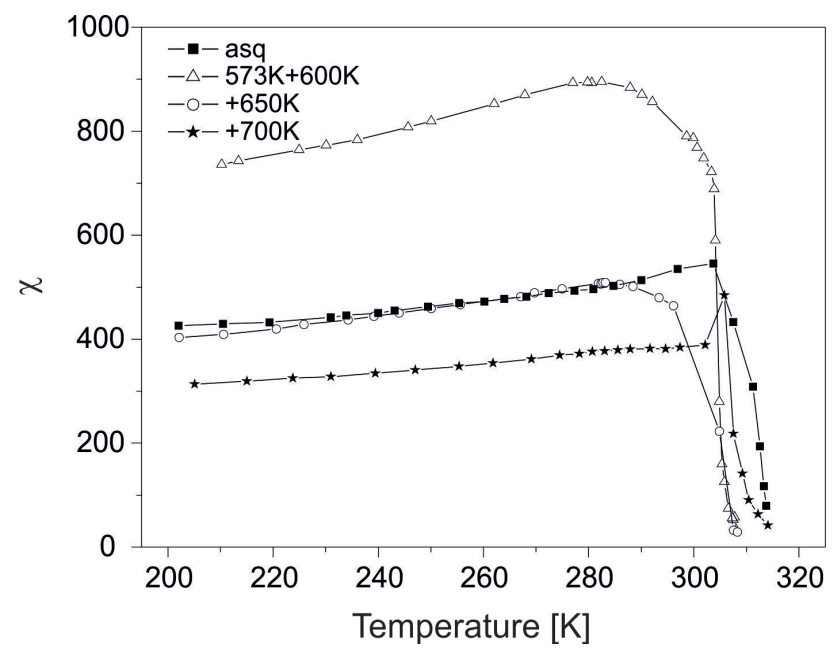

Fig. 7. Initial magnetic susceptibility of $\mathrm{Fe}_{86} \mathrm{Zr}_{7} \mathrm{Nb}_{1} \mathrm{Cu}_{1} \mathrm{~B}_{5}$ ribbons versus temperature in the as-quenched state and after annealing

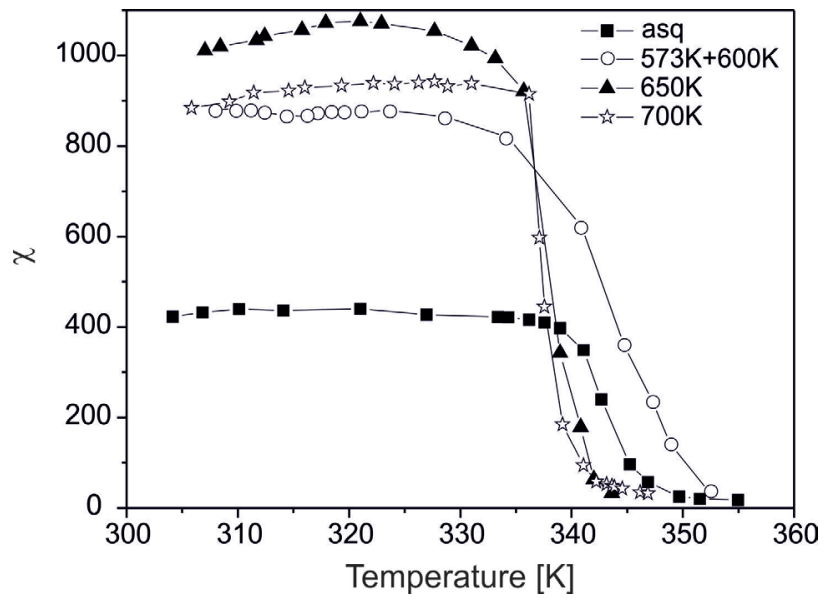

Fig. 8. Initial magnetic susceptibility of $\mathrm{Fe}_{82} \mathrm{Zr}_{7} \mathrm{Nb}_{2} \mathrm{Cu}_{1} \mathrm{~B}_{8}$ ribbons versus temperature in the as-quenched state and after annealing

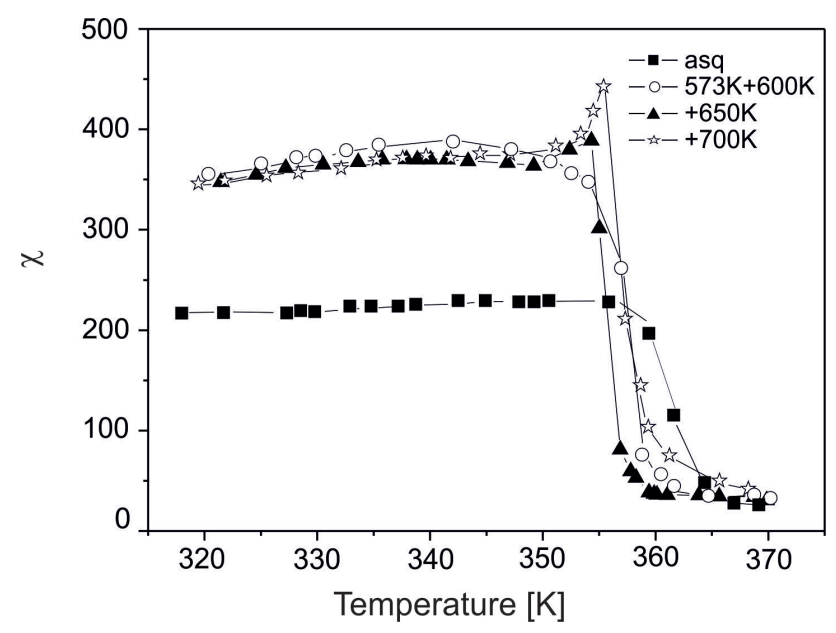

Fig. 9. Initial magnetic susceptibility of $\mathrm{Fe}_{81} \mathrm{Pt}_{5} \mathrm{Zr}_{7} \mathrm{Nb}_{1} \mathrm{Cu}_{1} \mathrm{~B}_{5}$ ribbons versus temperature in the as-quenched state and after annealing 
It is seen from these drawings that the heating treatment quite differently influence Curie temperature and susceptibility of the individual samples. A ferromagnetic - paramagnetic transition is indicated by a maximum on the $\chi(\mathrm{T})$ curve (so called Hopkinson maximum) [17] located nearly Curie temperature.

For the $\mathrm{Fe}_{86} \mathrm{Zr}_{7} \mathrm{Nb}_{1} \mathrm{Cu}_{1} \mathrm{~B}_{5}$ alloy the clear maximum may be found only on the $\chi(\mathrm{T})$ curve for the as quenched sample. After the treatment the maximum is staying wider, rather flat, and extended to lower temperatures. These flat maximum indicate that the sample is not homogeneous. First stage of the treatment lead to a significant, over two times at the maximum, increase of the susceptibility. The annealing gives rise to a relaxation of the samples and the susceptibility increase is an apparent manifestation of those processes. Further heating, in more elevated temperatures, trigger magnetic hardening of the sample. The susceptibilities are lowered below the level observed for aq sample and Hopkinson maximum again is sharp, well localized.

The change of the composition of the alloy notably alters $\chi$ on $\mathrm{T}$ dependence and its modification according the annealing. For the $\mathrm{Fe}_{82} \mathrm{Zr}_{7} \mathrm{Nb}_{2} \mathrm{Cu}_{1} \mathrm{~B}_{8}$ alloy there are flat maxima irrespective of the earlier treatment. The shift of the maximum to the lower temperatures, after treatment, is observed as compared with the aq alloy albeit this tendency is not stable with the increasing of the treatment temperature. The $T_{C}$ fixed for the alloy after a quarter at $700 \mathrm{~K}$ is higher than that for heated at $650 \mathrm{~K}$ however both are lower than for as quenched one. What should be noticed is considerably great softening of the material during treatment. Even after its first stages susceptibility increase exceeds 100 percents. Hardening effect is much smaller then observed in $\mathrm{Fe}_{86} \mathrm{Zr}_{7} \mathrm{Nb}_{1} \mathrm{Cu}_{1} \mathrm{~B}_{5}$ and, what is crucial; it is both slight and recorded only after the final treatment. This behavior is consistent with conclusions from Mössbauer spectra analysis. The alloy has much less strains and they are able to be relaxed in lower temperatures. The free volumes seem to be smaller and more stable.

An addition of $\mathrm{Pt}$ to the alloy make it magnetically harder (see figure 9). The value of the magnetic susceptibility for the not treated alloy is only slightly over 200 what is about half of the values for the other two alloys under consideration. Isothermal annealing increases this value by about, on average, 100 hundred. This rise is practically independent on the temperature of the treatment. This last factor influences only the shape of the $\chi(\mathrm{T})$ curve. The first two curves have very flat maxima but those related to material treated at $650 \mathrm{~K}$ or at $700 \mathrm{~K}$ exhibit very sharp maxima. Heating in every case but the two highest temperatures moves the Hopkinson's maximum to the lower temperature.

The Hopkinson's maximum may be considered as a indicator of the $T_{C}$ localization, but, especially for the very flat maxima, this is not exact method. Figures 10, 11, 12 summarized the results of specific magnetization, $\sigma(\mathrm{T})$, measurements in a constant, $0.75 \mathrm{~T}$, magnetic field.

For all the cases the magnetization is decreasing with temperature rising. To find the Curie temperature a linear dependence of $\sigma^{1 / \beta}$ from $T$ was assumed [18-19]. The critical parameter $\beta$ value was chosen to be equal 0.36 , as for Heisenberg type ferromagnetic. As is seen from the inserts on figures $9-11, \mathrm{~T}_{\mathrm{C}}$ for all the samples, despite the heat treatment, is higher than an ambient temperature. The obtained values are in very good agreement with those approximated from the $\chi(\mathrm{T})$ curves. This verifies the ferromagnetic, Heisenberg type, character of the samples as the calculations were done with such the assumption for $\beta$ parameter [20]. Curie temperature has its maximum value for as-quenched samples and is decreasing with addition of sequential treatment steps. The exception is for $\mathrm{Fe}_{81} \mathrm{Pt}_{5} \mathrm{Zr}_{7} \mathrm{Nb}_{1} \mathrm{Cu}_{1} \mathrm{~B}_{5}$ alloy for which aq sample has $\mathrm{T}_{\mathrm{C}}$ equal $303 \mathrm{~K}$, after two stages of the treatment $\mathrm{T}_{\mathrm{C}}$ decreased to $292 \mathrm{~K}$ and increased up to $305 \mathrm{~K}$ after annealing at $700 \mathrm{~K}$. The increase of a boron content gives rise of $\mathrm{T}_{\mathrm{C}}$. Values from $346 \mathrm{~K}$ (for aq) to $342 \mathrm{~K}$ (after the last stage of the treatment) were recorded. Even more substantial rise was observed in the $\mathrm{Fe}_{81} \mathrm{Pt}_{5} \mathrm{Zr}_{7} \mathrm{Nb}_{1} \mathrm{Cu}_{1} \mathrm{~B}_{5}$ case. The range of the $\mathrm{T}_{\mathrm{C}}$ is from $360 \mathrm{~K}$ to $352 \mathrm{~K}$.

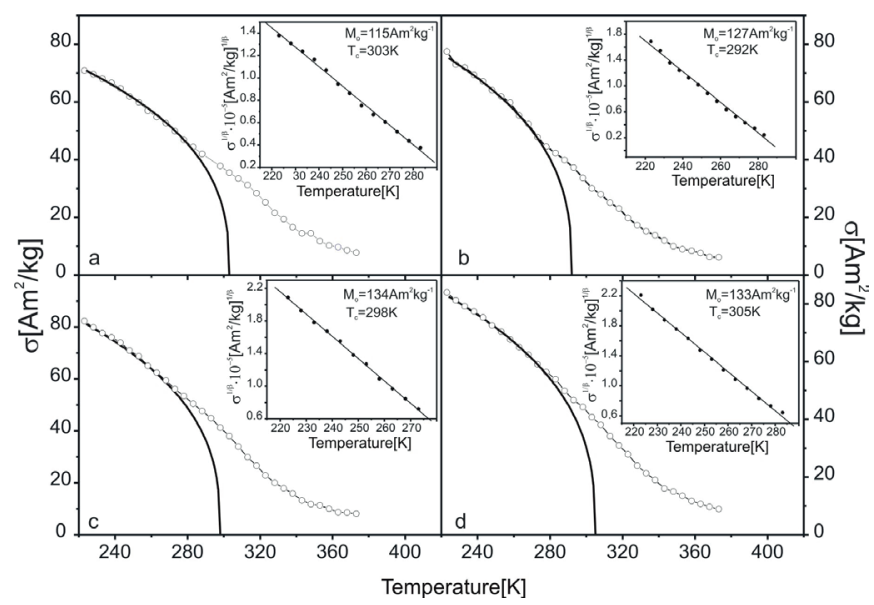

Fig. 10. Specific magnetization $(\sigma)$ versus temperature at $\mathrm{B}=0.75 \mathrm{~T}$ for the ribbons amorphous $\mathrm{Fe}_{86} \mathrm{Zr}_{7} \mathrm{Nb}_{1} \mathrm{Cu}_{1} \mathrm{~B}_{5}$ alloy in the as-quenched (a) state and after the annealing at $573 \mathrm{~K}+600 \mathrm{~K}$ (b), $650 \mathrm{~K}$ (c) and $700 \mathrm{~K}$ (d) for $15 \mathrm{~min}$. Critical behavior of magnetization to determine the Curie points is inserted as an inset

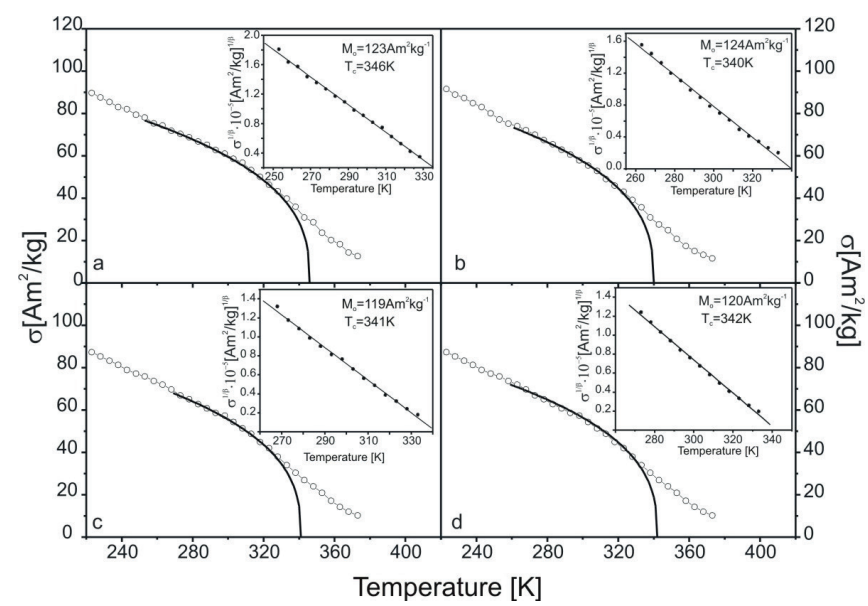

Fig. 11. Specific magnetization $(\sigma)$ versus temperature at $\mathrm{B}=0.75 \mathrm{~T}$ for the ribbons amorphous $\mathrm{Fe}_{82} \mathrm{Zr}_{7} \mathrm{Nb}_{2} \mathrm{Cu}_{1} \mathrm{~B}_{8}$ alloy in the as-quenched state and after the annealing at $573 \mathrm{~K}+600 \mathrm{~K}$ (b), $650 \mathrm{~K}$ (c) and $700 \mathrm{~K}$ (d) for $15 \mathrm{~min}$. Critical behavior of magnetization to determine the Curie points is inset 


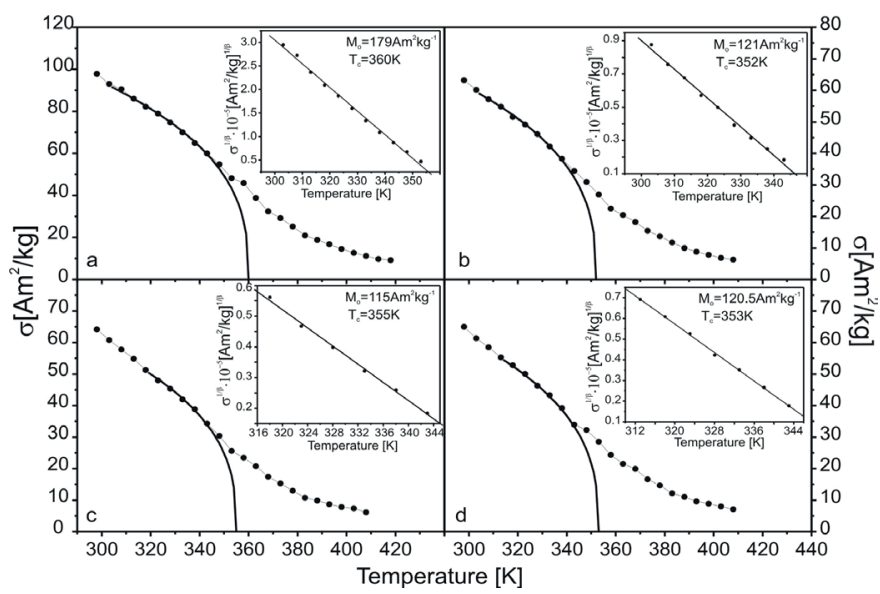

Fig. 12. Specific magnetization $(\sigma)$ versus temperature at $B=0.75 \mathrm{~T}$ for the ribbons amorphous $\mathrm{Fe}_{81} \mathrm{Pt}_{5} \mathrm{Zr}_{7} \mathrm{Nb}_{1} \mathrm{Cu}_{1} \mathrm{~B}_{5}$ alloy in the as-quenched state and after the annealing at $573 \mathrm{~K}+600 \mathrm{~K}$ (b), $650 \mathrm{~K}$ (c) and $700 \mathrm{~K}$ (d) for $15 \mathrm{~min}$. Critical behavior of magnetization to determine the Curie points is inset

\section{Conclusions}

The results of the both Mössbauer spectroscopy and HREM investigations confirm that the samples stay amorphous even after some steps of heating treatment. In the $\mathrm{Fe}_{86} \mathrm{Zr}_{7} \mathrm{Nb}_{1} \mathrm{Cu}_{1} \mathrm{~B}_{5}$ alloy, after fifteen minutes annealing at $700 \mathrm{~K}$, Mössbauer spectra indicated a presence of the precursors of the crystalline phase. The magnetic susceptibilities revel that heating treatment, after the first stages, improve soft magnetic properties - susceptibility of the sample increase around $100 \%$. The continuation of treatment, at higher temperatures partially cancels this effect. Strong magnetic hardening of the samples is observed. The analysis of the Hopkinson maxima on the $\chi(T)$ curves, which is located just above $T_{C}$, show that it moves to lower temperatures after the subsequent steps of treating. Substitution of additional $\mathrm{B}$ and $\mathrm{Nb}$ atoms in place of $\mathrm{Fe}\left(\mathrm{Fe}_{82} \mathrm{Zr}_{7} \mathrm{Nb}_{2} \mathrm{Cu}_{1} \mathrm{~B}_{8}\right)$ increase the susceptibility of the material and increase $\mathrm{T}_{\mathrm{C}}$ about $40 \mathrm{~K}$ in comparison with the value for the $\mathrm{Fe}_{86} \mathrm{Zr}_{7} \mathrm{Nb}_{1} \mathrm{Cu}_{1} \mathrm{~B}_{5}$. The hardening of the alloy starts at higher temperature. The third considered alloy, $\mathrm{Fe}_{81} \mathrm{Pt}_{5} \mathrm{Zr}_{7} \mathrm{Nb}_{1} \mathrm{Cu}_{1} \mathrm{~B}_{5}$, has the highest Curie temperature, $360 \mathrm{~K}$, and its susceptibility is significantly lower than those for the previous ones. The Curie temperatures obtained in this way are in fairly good agreement with those calculated from magnetization curves when we assume that critical parameter $\beta$ is equal to 0.36 , the value for Heisenberg type ferromagnetic phase.

\section{REFERENCES}

[1] J.M.D. Coey, Amorphous Solid and Liquid State 13, 433-466 (1985).

[2] S. N. Kaul, V. Siruguri, G. Chandra, Phys. Rev. B 45, 1234312356 (1992).

[3] V.A. Makarov, A.Ya. Belenkii, O.S. Kozlova, Phys. Stat. Sol. (A) 139, 173-179 (1993).

[4] M. Nabiałek, P. Pietrusiewicz, K. Błoch, M. Szota, Int. J. Mater. Res. 106, 682-688 (2015).

[5] P. Pietrusiewicz, M. Nabiałek, M. Szota, M. Dośpiał, K. Błoch, A. Bukowska, K. Gruszka, Arch. Metall. Mater. 59, 659-662 (2014).

[6] K. Gruszka, M. Nabiałek, K. Błoch, J. Olszewski, Nukleonika 60, 23-27 (2015)

[7] P. Pietrusiewicz, K. Błoch, M. Nabiałek, S. Walters, Acta Phys. Pol. A 127, 397-399 (2015).

[8] A. P. Thomas, M.R.J. Gibbs, J. Magn. Magn. Mater. 103, 97110 (1992).

[9] K. Błoch, J. Magn. Magn. Mater. 390, 118-122 (2015).

[10] J. Gondro, K. Błoch, M. Nabiałek, K. Waltters, M. Szota, Arch. Metall. Mater. 60, 1071-1074 (2015).

[11] M. Al.-Haj, J. Barry, J. Mat. Sci. Lett. 17 (1998) 1125-1127.

[12] R.A. Brand, Nucl Instrum Meth B 28, 398-416 (1987).

[13] G. H'ohne, W. Hemminger, H.J. Flammersheim, second edition, Springer-Verlag, Berlin (2003).

[14] J. Gondro, J. Świerczek, J. Rzcki, W. Ciurzyriska, J. Olszewski, J, Zbroszczyk, K. Bloch, M. Osyra A. Łukiewska, J.Magn. Magn. Mater. 341, 100-107 (2013).

[15] J. Zbroszczyk, L. K. Varga, J. Olszewski, W. H. Ciurzyńska, J. Phys. IV 8, 203-206 (1998).

[16] J. Gondro, J. Świerczek, K. Błoch, J. Zbroszczyk, W. Ciurzyńska, J. Olszewski, Physica B 445, 37-41 (2014).

[17] H.W. Kwon, S. W. Shon, J. Magn. 6, 61-65 (2001).

[18] R. Meyer, H. Kronmüller, Phys. Stat. Sol. B 109, 693-703 (1982).

[19] S.N. Kaul, Phys. Rew. B 22, 278-287 (1980).

[20] S.N. Kaul, J.Magn. Magn. Mater. 53, 5-53 (1985). 
